\title{
Microbiota intestinal humana y dieta
}

\author{
Human gut microbiota and diet
}

Carlos Alberto Padrón Pereira

Asociación RVCTA. Avenida Andrés Bello No 101-79, Sector La Pastora, Municipio Valencia, Estado Carabobo, C. P. 2001, República Bolivariana de Venezuela. carlospadron1@gmail.com

Rec.: 18.01.2018. Acept.: 06.06.2019. Publicado el 30 de julio de 2019

\section{Resumen}

$\mathrm{L}$ a dieta es un factor que impulsa la composición y el metabolismo de la microbiota intestinal (M-I), y los macronutrientes ejercen un gran impacto en la (M-I). Los carbohidratos no digeribles pueden producir marcados cambios en la (M-I), las fibras dietéticas son los principales impulsores de la composición y función de la (M-I), permiten estimular el predominio de una (M-I) capaz de utilizar estos sustratos como fuente de energía, pero estos efectos dependen tanto del tipo de fibra como de la composición inicial de la (M-I) de un individuo. El metabolismo proteico por la (M-I) da como resultado productos adicionales, algunos de los cuales son potencialmente dañinos para la salud del huésped. Firmicutes, Bacteroidetes y Actinobacteria son los tres filos principales que habitan en el intestino grueso humano. El género Bacteroides se asocia con dietas basadas en carne, las familias Ruminococcaceae y Lachnospiraceae con dietas ricas en polisacáridos complejos de plantas y el género Prevotella con dietas altas en azúcar pero bajas en grasas y proteínas. La dieta puede usarse para modular la composición y el metabolismo de la (M-I). Una estrategia dietética para modular (M-I) es el consumo de fibra dietética y prebióticos. Esta revisión tiene como objetivo describir conocimiento sobre la (M-I), orientado hacia un uso de la dieta para proporcionar beneficios a la salud humana..

Palabras clave: alimentos saludables, bacterias intestinales, diversidad microbiana, fibras dietéticas, patrones dietéticos, salud.
$\mathrm{D}$ iet is a factor driving the composition and metabolism of the gut microbiota, and macronutrients have a great impact on microbiota. Dietary non-digestible carbohydrate can produce marked changes in the gut microbiota, dietary fibers are major drivers of gut microbiota composition and function, stimulating the dominance of bacteria able to utilize these substrates as energy source, but these effects depend on both the type of fiber and the initial composition of an individual's gut microbiota. Protein metabolism by gut microbiota results in additional products, some of which are potentially harmful to host health. Firmicutes, Bacteroidetes and Actinobacteria are the three major phyla that inhabit the human large intestine. The genera Bacteroides is associated with meat-based diets, the families Ruminococcaceae and Lachnospiraceae are associated with diets rich in complex plant polysaccharides, and the genera Prevotella is associated with diets high in sugar but low in fat and protein. Diet can be used to modulate the composition and metabolism of the gut microbiota. One dietary strategy for modulating the microbiota is consumption of dietary fiber and prebiotics. This review aims at describing knowledge about gut microbiota, oriented towards a use of diet to provide benefits to human health.

Key words: healthy foods, gut bacteria, microbial diversity, dietary fibers, dietary patterns, health. 


\section{Introducción}

$\mathrm{L}$ a microbiota intestinal humana está influenciada

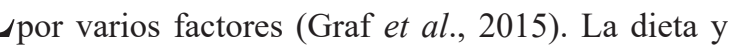
el estilo de vida moderna, entre otros, ha contribuido a generar un cambio en los patrones de colonización microbianos alterando la composición de la microbiota. La dieta es considerada como uno de los principales impulsores en la conformación de la microbiota intestinal a lo largo de la vida (Thursby y Juge, 2017). La relación existente entre la microbiota intestinal, la salud y la enfermedad, al mismo tiempo se relaciona con diferentes patrones alimentarios, entre ellos los caracterizados por abundancia de cereales, tubérculos, frutas y otros vegetales, y los que se basan en un consumo de alimentos refinados, carnes y otros productos de origen animal.

Como las bacterias se especializan en la fermentación de diferentes sustratos, las dietas pueden proporcionar una gama de factores promotores del crecimiento y de inhibición del crecimiento para filotipos específicos (Flint et al., 2012; Graf et al., 2015). La interacción entre componentes de la dieta y la microbiota intestinal podría ser, en parte, responsable de sus beneficios para la salud (Etxeberria et al., 2016).

Por evidencias de que alteraciones dietéticas producen cambios en la microbiota intestinal, existe un marcado interés sobre el papel de los microorganismos en la fisiología humana y diversas estrategias se han desarrollado para intentar corregir trastornos modulando la composición de la microbiota intestinal.

La literatura sobre estudios experimentales y clínicos orientados a describir los efectos de la microbiota en respuestas fisiológicas de los huéspedes es abundante y los descubrimientos están abriendo nuevos caminos en la comprensión de diversas enfermedades inflamatorias y metabólicas, entre otras. Preponderantemente se ha manifestado en la literatura el interés sobre cómo la dieta influye en la composición $\mathrm{y}$ funcionalidad de la microbiota intestinal.

Para la revisión se consultó literatura disponible en bases de datos, complementariamente, con opciones de búsqueda de artículos publicados por editoriales; PubMed, Nature Research/Springer Nature, British Journal of Nutrition, Science/AAAS, entre otras.

El objetivo de esta revisión es resumir parte de la evidencia de estudios en humanos publicados sobre el papel de la dieta en la composición de la microbiota intestinal, orientados hacia la salud humana.

\section{Microbiota intestinal y dieta}

Los microorganismos colonizan prácticamente todas las superficies del cuerpo humano que están expuestas al entorno externo; incluye la piel, la cavidad oral, el tracto respiratorio, urogenital y el gastrointestinal. El tracto gastrointestinal es el más densamente colonizado y la compleja comunidad de microorganismos que allí reside o pasa a través de ella se conoce como microbiota intestinal (Gerritsen et al., 2011).

En el vocabulario utilizado para describir las comunidades microbianas, la palabra microbiota representa un conjunto de microorganismos que reside en un entorno previamente establecido, como el intestino humano; y el microbioma comprende todo el material genético dentro de una microbiota.

Las bacterias que viven en nuestros intestinos, antes "flora intestinal" o "microflora intestinal", ahora "microbiota intestinal", se desarrollan posterior al nacimiento ya que nacemos estériles. En un bebé amamantado la microbiota será principalmente bifidobacterias y será diferente a la de un bebé alimentado con fórmulas para lactantes. Al transcurrir el tiempo la microbiota es influenciada por la dieta, el entorno, el uso de antibióticos. Como adultos jóvenes, nuestra microbiota intestinal contiene 100 billones de microorganismos, incluyendo como mínimo 1000 especies diferentes de bacterias. Solo $1 / 3$ es común en todas las personas y los otros $2 / 3$ son específicos de cada persona. Con el paso de los años, como personas mayores, la microbiota será diferente a la de adultos jóvenes. No obstante, de acuerdo con Bian et al. (2017), en el caso de personas mayores saludables, la microbiota puede ser similar a la de adultos jóvenes saludables. El ecosistema microbiano que se encuentra en personas extremadamente ancianas, está enriquecido en Akkermansia, Bifidobacterium y la familia Christensenellaceae, asociadas a la salud (Biagi et al., 2016). Existe relación entre la dieta, la microbiota y el estado de salud, e indica un papel para las alteraciones de la microbiota impulsadas por la dieta en diferentes tasas de deterioro de la salud con el envejecimiento (Claesson et al., 2012).

La microbiota intestinal desempeña un papel en los procesos metabólicos, nutricionales, fisiológicos e inmunológicos en el cuerpo humano. Participa en la defensa contra patógenos por mecanismos como la resistencia a la colonización y la producción de compuestos antimicrobianos. Además, la microbiota intestinal participa en el desarrollo, la maduración y el mantenimiento de las funciones sensoriales y motrices gastrointestinales, la barrera intestinal y el sistema inmune de la mucosa (Gerritsen et al., 2011).

La microbiota puede adaptar su composición a la dieta, p. ej., japoneses pueden digerir algas marinas de su dieta diaria gracias a enzimas que su microbiota ha adquirido de bacterias marinas (Hehemann et al., 2010; 


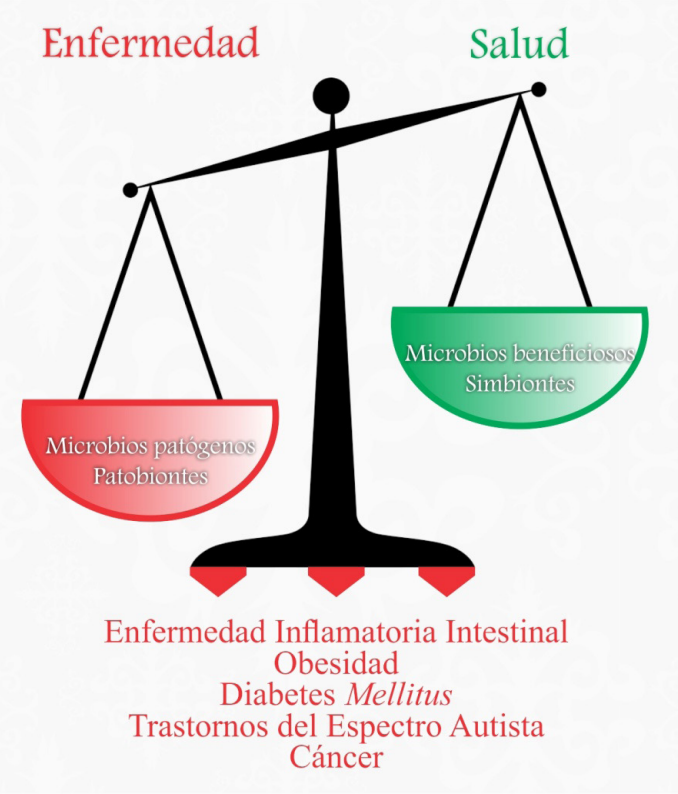

Figura 1. Disbiosis de la microbiota intestinal manifestada como aumento de bacterias causantes de enfermedades

Nishijima et al., 2016). La microbiota puede adaptarse, no obstante, también puede ocurrir una pérdida de balance en su composición que tiene relación con el equilibrio entre las bacterias beneficiosas (salud) y las patógenas (enfermedad) en la microbiota, una alteración conocida como disbiosis intestinal, y esto, genera problemas de salud de todo tipo. En el mismo sentido, la disbiosis puede manifestarse como el aumento de las bacterias causantes de enfermedades (Figura 1), la disminución de especies bacterianas beneficiosas para la salud y/o la reducción de la diversidad de especies bacterianas. Los problemas de salud son innumerables $\mathrm{y}$ entre las opciones para restablecer el balance se encuentran: una buena nutrición, los probióticos, prebióticos y posbióticos.

Los probióticos son microorganismos vivos (en la mayoría de los casos, bacterias) que son similares a los microorganismos beneficiosos que se encuentran en el intestino humano. También se les llama "bacterias amigas" o "buenas bacterias". Los probióticos están disponibles para los consumidores principalmente en forma de suplementos dietéticos y alimentos (NCCIH, 2018). La actual definición de probióticos es: "microorganismos vivos que, cuando se administran en cantidades adecuadas, confieren un beneficio para la salud del huésped" (Hill et al., 2014). Los prebióticos son ingredientes alimentarios no digeribles que estimulan el crecimiento de bacterias bifidogénicas y ácido lácticas en el tracto gastrointestinal. Típicamente, los prebióticos consisten en fibras dietéticas y oligosacáridos (Patel y Goyal, 2012). No todas las fibras se pueden clasificar como prebióticas; sin embargo, la mayoría de los prebióticos se pueden clasificar como fibras dietéticas (Slavin, 2013). Un panel de expertos en microbiología, nutrición e investigación clínica actualizó la definición de prebiótico: "un sustrato que es utilizado selectivamente por microorganismos huéspedes que confieren un beneficio para la salud". Mientras que los probióticos son microorganismos vivos que benefician la salud del huésped, los prebióticos no, sino sustratos que sirven como nutrientes para los microorganismos beneficiosos albergados por el huésped (Gibson et al., 2017). La introducción de probióticos (especies bacterianas "benéficas" como Bifidobacterium bifidum) o la adición de prebióticos (como fructooligosacáridos) que promueven el crecimiento y la actividad de ciertas especies bacterianas son los métodos convencionales para manipular la comunidad microbiana intestinal. Los avances en la secuenciación de alto rendimiento y la metabolómica han llevado a la aparición de posbióticos que se pueden utilizar para manipular directa y específicamente la función de la microbiota (Klemashevich et al., 2014). Los posbióticos son productos finales metabólicos de las bacterias, entre ellos el butirato, que se produce a partir de fibra dietética, y cuando está presente en cantidad suficiente, se convierte en la principal fuente de energía para células epiteliales colónicas; por otro lado el propionato, que se transfiere al hígado donde sirve como precursor de la gluconeogénesis hepática (Schnorr et al., 2014) y el acetato, que cumple un papel en la capacidad de las bifidobacterias para inhibir enteropatógenos (Fukuda et al., 2011). El butirato, propionato y acetato, que son ácidos grasos de cadena corta, productos principales de la fermentación de la fibra dietética en el intestino grueso, desempeñan un papel importante en el mantenimiento de la función de la barrera intestinal (Kiefer et al., 2006; Chen et al., 2017); fundamentales en aspectos fisiológicos del hospedador, tales como, la adquisición de nutrientes, la función inmune, la señalización celular, el control de la proliferación y protección de patógenos (Schnorr et al., 2014).

La mayor parte de la microbiota intestinal reside en el intestino grueso; ubicación principal de la fermentación bacteriana (Korpela, 2018).

Las especies bacterianas dominantes en el tracto gastrointestinal humano se dividen en 3 filos: el filo Firmicutes (p. ej., Ruminococcus, Clostridium, Eubacteria), el filo Bacteroidetes (p. ej., Porphyromonas, Prevotella) y el filo Actinobacteria (Bifidobacterium) (Rajoka et al., 2017); Proteobacteria, Fusobacteria, Cianobacteria y Verrucomicrobia suelen estar menos representados (D’Argenio y Salvatore, 2015). El único representante conocido del filo Verrucomicrobia es Akkermansia muciniphila (Hugon y Salvatore, 


\section{Microbiota Intestinal}

\section{Comunidades microbianas dominantes}

$$
\begin{gathered}
(98 \%) \\
\text { ㅁ․ }
\end{gathered}
$$

Firmicutes (de $30 \%$ a $52 \%$ )

Bacteroidetes (de $9 \%$ a $42 \%$ )

Actinobacteria (de $1 \%$ a $13 \%$ )

Proteobacteria

\section{Otros microorganismos}

$(2 \%)$

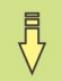

Lactobacillus (2\%)

Streptococcus (2\%)

Enterobacteriaceae (1\%)

Akkermansia muciniphila

(Verrucomicrobia)

Figura 2. Composición de la microbiota intestinal. Modificado de Rajoka et al. (2017) y con información de Hugon y Salvatore (2015).

2015). Otras bacterias, tales como Lactobacillus, Streptococcus y Escherichia coli (Enterobacteriaceae) se encuentran en menor cantidad. Con base en la evidencia de las tecnologías genómicas, se encontró que los filos Firmicutes y Bacteroidetes son las poblaciones bacterianas dominantes en el tracto gastrointestinal (Figura 2) (Rajoka et al., 2017).

La microbiota se agrupa de acuerdo con patrones de dietas basadas en plantas o en animales. La diversidad bacteriana en mamíferos es más alta entre los herbívoros, seguidos de omnívoros y luego carnívoros (Ley et al., 2008), además, composicional y funcionalmente distinta (Muegge et al., 2011).

Schnorr et al. (2014) caracterizaron la microbiota intestinal de los Hadza en Tanzania (cazadoresrecolectores) en comparación con la de italianos en Bolonia. La dieta Hadza consiste en alimentos silvestres que se dividen en 5 categorías principales: carne, miel, baobab, bayas y tubérculos. No practican ningún cultivo o domesticación de plantas y animales, y reciben un mínimo de cantidades de productos agrícolas de fuentes externas. En comparación, la dieta italiana es casi en su totalidad productos agrícolas comerciales y se adhiere en gran medida a la dieta mediterránea: abundantes plantas, fruta fresca, pasta, pan y aceite de oliva; cantidades bajas a moderadas de productos lácteos, aves de corral, pescado y carne roja; la mayoría de los carbohidratos basados en almidón fácilmente digerible, azúcar y muy poca fibra soluble o insoluble. Firmicutes y Bacteroidetes fueron los filos dominantes en la microbiota intestinal tanto en los Hadza como en los italianos; Hadza se caracterizó por una relativamente mayor abundancia de Bacteroidetes y menor de Firmicutes. Hadza mostró mayor enriquecimiento en los filos Proteobacteria y Spirochaetes, que fueron extremadamente raros en la microbiota italiana, mientras que el filo Actinobacteria, una componente subdominante importante de la microbiota italiana, estuvo casi completamente ausente en la microbiota Hadza. A nivel de género, la microbiota intestinal Hadza estuvo comparativamente enriquecida en Prevotella, Eubacterium, Oscillibacter, Butyricicoccus, Sporobacter, Succinivibrio, Treponema y agotada en Bifidobacterium, Bacteroides, Blautia, Dorea, Lachnospiraceae no clasificada, Roseburia, Faecalibacterium, Ruminococcus y Erysipelotrichaceae no clasificada. Además de muchos géneros no clasificados pertenecientes a Bacteroidetes, el orden Clostridiales y la familia Ruminococcaceae.

Una variedad de fibras dietéticas (p. ej., celulosa, hemicelulosas, pectinas, gomas, fructanos) y almidones resistentes en la dieta, que contienen una gama de unidades de monosacáridos y enlaces $\alpha$ y $\beta$, es más compatible con una variada comunidad microbiana gastrointestinal en comparación con una dieta que tiene una carga de sustrato menos diversa (p. ej., dietas refinadas) (Holscher, 2017).

De Filippo et al. (2010) caracterizaron la microbiota fecal de niños sanos del grupo étnico Mossi en Burkina Faso en comparación con la de niños sanos del área urbana de Florencia en Italia. La dieta de los niños Mossi es baja en grasas y proteínas animales, rica en almidón, fibra y polisacáridos 
vegetales; predominantemente vegetariana. Todos los recursos alimenticios son completamente producidos localmente; granos de mijo, sorgo, leguminosas y otros vegetales, por lo que el contenido de carbohidratos, fibra y proteína vegetal es muy alto. A veces consumen una pequeña cantidad de pollo y termitas en temporada de lluvias. Los niños son amamantados hasta la edad de 2 años como complemento a una dieta mixta. La cantidad promedio de fibra en la dieta es $10.0 \mathrm{~g} / \mathrm{d}$ en niños de 1 a 2 años y $14.2 \mathrm{~g} / \mathrm{d}$ en niños de 2 a 6 años. La dieta de los niños italianos es alta en proteína animal, azúcar, almidón, grasa y baja en fibra. Los niños amamantados hasta 1 año de edad. La cantidad promedio de fibra en la dieta es $5.6 \mathrm{~g} / \mathrm{d}$ en niños de 1 a 2 años y $8.4 \mathrm{~g} / \mathrm{d}$ en niños de 2 a 6 años. Diferencias relevantes se encontraron en los filos. Actinobacteria y Bacteroidetes estuvieron más representados en la microbiota de los niños Mossi que en la de los niños italianos con abundancia única de bacterias del género Prevotella y Xylanibacter, que se sabe contienen un conjunto de genes bacterianos para la hidrólisis de celulosa y xilano; completamente ausentes en los niños italianos. Shigella y Escherichia (Enterobacteriaceae) estuvieron significativamente subrepresentadas en los niños Mossi. Los filos Firmicutes y Proteobacteria fueron más abundantes en los niños italianos. La distribución diferencial de Firmicutes y Bacteroidetes marcó las profundas diferencias entre los 2 grupos.

La acumulación de datos sugiere que, entre las poblaciones occidentales, Bacteroides se asocia con dietas basadas en carne, Ruminococcaceae y Lachnospiraceae con dietas ricas en polisacáridos complejos de plantas y Prevotella con dietas altas en azúcar pero bajas en grasas y proteínas (Korpela, 2018).

Efectos bifidogénicos se han observado en adultos que consumieron manzanas (Shinohara et al., 2010) y bananas (Mitsou et al., 2011). La jalea de hipocolitos de maca (Lepidium meyenii) ejerció un efecto bifidogénico cuando se incorporó a yogur, por incrementos en los recuentos de Bifidobacterium bifidum (León-Marroú, 2011).

Se han observado disminuciones en la abundancia del grupo Clostridium en estudios que complementan el afrecho de arroz, garbanzos, manzanas, hongos, y frutas $\mathrm{y}$ otros vegetales bajos en contenidos de flavonoides (Sheflin et al., 2017).

En la microbiota intestinal, niveles más altos de bacterias ácido lácticas, coliformes y estafilococos, y ninguna diferencia en enterococos, se encontraron en niños que viven en zona rural de Tailandia en comparación con zona urbana en Singapur. Las diferencias pueden ser explicadas por el contraste de los factores medioambientales y prácticas de estilo de vida entre las 2 regiones; posiblemente fuente de agua potable y uso de antibióticos (Mah et al., 2008).

Se está investigando la relación entre la salud humana y taxones bacterianos comunes encontrados en la microbiota humana. Enfermedades crónicas como la obesidad, enfermedad inflamatoria intestinal, diabetes mellitus, síndrome metabólico, aterosclerosis, enfermedad hepática alcohólica, cirrosis y el carcinoma hepatocelular se han asociado con la microbiota humana (Wang et al., 2017). Las personas con exceso de peso presentan diferencias en la microbiota con relación a personas delgadas. La manipulación dietética de la microbiota a través de estrategias que favorezcan el crecimiento de las bacterias "beneficiosas" frente a las descritas como "patógenas" se considera una alternativa potencial a la hora de tratar o prevenir el desarrollo de diversas patologías como la obesidad (Etxeberria et al., 2016). Mayor abundancia de Akkermansia muciniphila se asocia con un estado metabólico más saludable en humanos con sobrepeso/obesos (Dao et al., 2016).

Los efectos del predominio o disminución de comunidades de distintos filos pueden ser transgeneracionales. Y cabe destacar que, la biodiversidad medioambiental contribuye a dar forma a la microbiota humana y las diferencias en la abundancia y diversidad bacterianas están asociadas con la salud. En consecuencia, cambios en la comunidad microbiana medioambiental en áreas contaminadas pueden llevar a efectos similares en la comunidad microbiana humana y las consiguientes consecuencias para la salud (Parajuli et al., 2017). Además, diferencias en las estructuras sociales pueden influir en el alcance de la transmisión de la microbiota y el flujo de microbios y genes microbianos entre miembros de un hogar. Diferencias en las tradiciones culturales también afectan al alimento, la exposición a mascotas y ganado, y muchos otros factores que podrían influir en cómo y desde dónde una microbiota intestinal/microbioma se adquiere (Yatsunenko et al., 2012).

\section{Química de la dieta y microbiota intestinal}

La microbiota intestinal ejerce importantes actividades metabólicas mediante la extracción de energía en polisacáridos de la dieta que de otra forma no serían digeribles, como el almidón resistente y las fibras dietéticas. Estas actividades metabólicas también conducen a la producción de nutrientes importantes, como los ácidos grasos de cadena corta (AGCC), vitaminas (p. ej., vitamina $\mathrm{K}$, vitamina B12, ácido fólico) y aminoácidos, que los humanos no pueden producir por sí mismos (Gerritsen et al., 2011).

Las proteínas, grasas y carbohidratos son los 
principales componentes en las dietas de los humanos. El tipo y la cantidad de proteínas, grasas y carbohidratos presentes en la dieta influyen en la composición de la microbiota intestinal en el huésped. Este efecto está relacionado con los metabolitos de los componentes presentes en las dietas. Los AGCC, predominantemente acetato, propionato y butirato, son productos finales de la degradación de proteínas y carbohidratos en el tracto gastrointestinal, mediada por microorganismos. Los AGCC producidos por la microbiota son los metabolitos más extensamente estudiados de las dietas y ha sido encontrado que tienen un efecto fisiológico en la salud del huésped (Macfarlane y Macfarlane, 2012; Rajoka et al., 2017). Las concentraciones de todos los AGCC son típicamente más altas en el colon proximal (primera parte y parte media del intestino grueso) donde la fermentación es mayor y la cantidad presente se relaciona con el suministro de carbohidratos en la dieta. En humanos, la abundancia de AGCC es típicamente acetato $>$ propionato $>$ butirato (Lockyer $\mathrm{y}$ Nugent, 2017). En relación con el trabajo de De Filippo et al. (2010), se encontraron más AGCC en los niños Mossi que en los niños italianos; y en el de Schnorr et al. (2014), los italianos se caracterizaron por una mayor abundancia de butirato, mientras que los Hadza en propionato. Estas diferencias reflejaron la variación de la dieta en la cantidad y el tipo de fibra y carbohidratos consumidos por ambos grupos.

Entre los patrones dietéticos, alto consumo de carbohidratos complejos se asocia con Prevotella, mientras que alto consumo de grasa/proteína con Bacteroides. (Wu et al., 2011). En general, resultados indican que Bacteroides, junto con Alistipes y Parabacteroides, puede ser el taxón proteolítico primario en el intestino grueso de humanos (Korpela, 2018).

El consumo de suero lácteo y extracto proteínico de guisantes verdes (Pisum sativum) incrementa a las bacterias comensales Bifidobacterium y Lactobacillus, y adicionalmente el suero lácteo disminuye a las bacterias patógenas Bacteroides fragilis y Clostridium perfringens (Świątecka et al., 2011; Singh et al., 2017). Por el contrario, anaerobios como Alistipes, Bilophila wadsworthia y Bacteroides se incrementan con el consumo de dietas basadas en animales (Figura 3); Alistipes putredinis y Bacteroides spp. son microorganismos putrefactivos (David et al., 2014). Varios géneros microbianos promovidos por la ingesta de una dieta omnívora se han asociado con incremento en los niveles del N-óxido de trimetilamina; compuesto proaterogénico que aumenta el riesgo de enfermedad cardiovascular (De Filippis et al., 2016). Las proteínas derivadas de plantas se asocian con una menor mortalidad que las proteínas derivadas de animales (Levine et al., 2014).

La grasa de la dieta normalmente es absorbida en el intestino delgado, y solo pequeñas cantidades alcanzan el intestino grueso. La grasa no es una fuente de energía primaria para la microbiota colónica (Korpela, 2018).

El consumo de una dieta baja en grasas condujo a una mayor abundancia de Bifidobacterium con reducciones concomitantes en glucosa y colesterol total, en comparación con el valor inicial. Por otro lado, una dieta alta en grasas saturadas aumentó la proporción relativa de Faecalibacterium prausnitzii; y sujetos con ingesta alta de grasas monoinsaturadas no experimentaron cambios en la abundancia relativa de cualquier género bacteriano (Fava et al., 2013; Singh et al., 2017). Existe un creciente interés en $F$. prausnitzii, una de las especies bacterianas más abundantes que se encuentran en el intestino, dado su papel potencialmente importante en la promoción de la salud intestinal (LopezSiles et al., 2017). El consumo de dietas altas en grasas saturadas y trans aumenta el riesgo de enfermedades cardiovasculares a través de la regulación al alza del colesterol total y lipoproteínas de baja densidad ('low

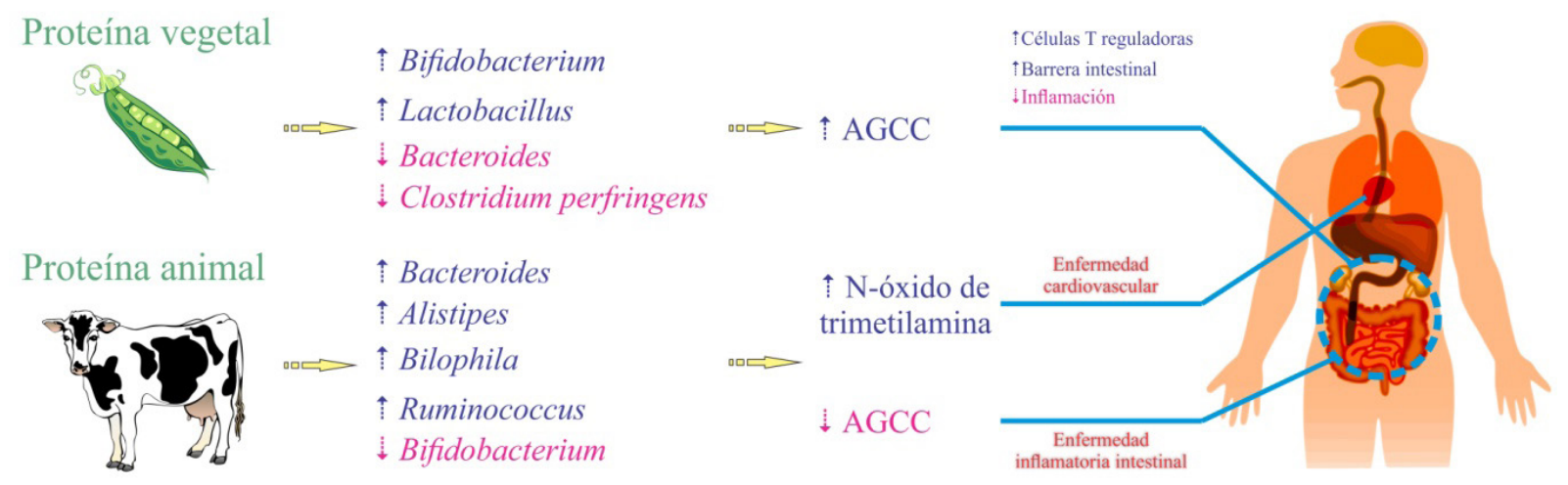

Figura 3. Impacto de la proteína dietética en la microbiota intestinal y resultados de salud. Modificado de Singh et al. (2017). 
density lipoproteins', LDL) en la sangre. Las dietas ricas en grasa interactúan de diversas maneras con la microbiota intestinal para facilitar la translocación de los lipopolisacáridos bacterianos que contribuyen a la generación de inflamación crónica (Sheflin et al., 2017). Por otro lado, las grasas promotoras de la salud, como las grasas monoinsaturadas y poliinsaturadas, son cruciales para aliviar el riesgo de enfermedades crónicas. La dieta occidental típica es alta en grasas saturadas, trans y baja en grasas monoinsaturadas, poliinsaturadas, por lo que predispone a los consumidores habituales a muchos problemas de salud (Singh et al., 2017).

Los carbohidratos digeribles se degradan enzimáticamente en el intestino delgado e incluyen almidones y azúcares. Tras la degradación, estos compuestos liberan glucosa en el torrente sanguíneo y estimulan una respuesta a la insulina. Los humanos alimentados con altos niveles de glucosa, fructosa y sacarosa, en forma de frutas de estación o temporada, aumentan la abundancia relativa de Bifidobacterium y reducen Bacteroides (Singh et al., 2017).

A diferencia de los carbohidratos digeribles, los carbohidratos no digeribles como la fibra y el almidón resistente no se degradan enzimáticamente en el intestino delgado, sino que llegan al intestino grueso donde se someten a la fermentación por parte de los microorganismos residentes produciendo AGCC (Lockyer y Nugent, 2017). En consecuencia, la fibra dietética es buena fuente de "carbohidratos accesibles a la microbiota", que pueden ser utilizados por los microorganismos para proporcionar al huésped energía y fuente de carbono. En el proceso, pueden modificar el entorno intestinal. Esta propiedad de las fibras garantiza su designación como prebióticos, que por definición son componentes dietéticos no digeribles que benefician la salud del huésped a través de la estimulación selectiva del crecimiento y/o la actividad de ciertos microorganismos. Las fuentes de prebióticos incluyen la soya, inulinas, trigo y cebada sin refinar, avena cruda y oligosacáridos no digeribles como los fructanos, polidextrosa, fructooligosacáridos, galactooligosacáridos, xilololosacáridos y arabinooligosacáridos (Singh et al., 2017). El consumo de cereales de maíz integral aumenta a Bifidobacterium spp. y Atobium spp., y el de trigo integral, la abundancia de lactobacilos y enterococos, además de Bifidobacterium spp. (Sheflin et al., 2017). Las dietas de carbohidratos no digeribles que son ricas en grano integral y afrecho de trigo están relacionadas con un aumento en el intestino de bifidobacterias y lactobacilos (Costabile et al., 2008); este efecto prebiótico sobre bifidobacterias también ha sido observado con grano integral de maíz, lo que resultó en un cambio beneficioso en la microbiota (Carvalho-Wells et al., 2010). El consumo de otros car- bohidratos no digeribles, como la cebada de grano entero, resulta en enriquecimiento de los géneros Roseburia, Bifidobacterium, Dialister y las especies Eubacterium rectale, Roseburia faecis y Roseburia intestinalis (Keim y Martin, 2014); y el almidón resistente incrementa a Ruminococcus bromii y Eubacterium rectal (Walker et al., 2011; Sheflin et al., 2017). Versiones integrales de alimentos con almidón (p. ej., pasta de trigo integral, arroz integral) contienen más almidón resistente que las versiones refinadas (Lockyer y Nugent, 2017). Los carbohidratos no digeribles pueden producir marcados cambios en la microbiota intestinal, pero son dependientes de la composición inicial de la microbiota intestinal individual (Walker et al., 2011). El consumo de granos enteros y carbohidratos complejos no digeribles encontrados en granos integrales puede cambiar significativamente la ecología microbiana del intestino grueso (Keim y Martin, 2014). Cabe destacar que, R. bromii es una especie clave que inicia la degradación del almidón resistente y produce subproductos que son más fácilmente utilizados por otras especies intestinales (Sheflin et al., 2017); y en el mismo sentido, bifidobacterias y lactobacilos metabolizan fructanos para producir lactato y acetato, como productos finales, que luego son utilizados por muchas otras bacterias, incluidas Roseburia, Eubacterium y Faecalibacterium, que producen butirato (Holscher, 2017).

Entre los efectos de dietas muy bajas en carbohidratos, en la microbiota intestinal ocurre disminución en la abundancia de bacterias productoras de butirato (Roseburia, Eubacterium rectale, Bifidobacterium), y por ende, de butirato. El aumento de la ingesta de fibra dietética no ha demostrado tener un efecto bifidogénico, pero se ha asociado con un aumento en la riqueza $y / o$ diversidad microbiana intestinal, especialmente en individuos con una diversidad reducida inicialmente (Sheflin et al., 2017). Existe evidencia de que el almidón resistente puede contrarrestar los efectos perjudiciales de la alta ingesta de carne roja en el riesgo de cáncer colorrectal (Lockyer y Nugent, 2017). Después de un alto consumo de carne y en ausencia de carbohidratos fermentables, la carne roja puede producir aductos de ADN promutagénicos y alterar la composición de la microbiota. Por lo tanto, una dieta alta en proteínas y baja en carbohidratos puede alterar la microbiota colónica favoreciendo un perfil de microbiota más proinflamatoria y una menor producción de AGCC. El consumo en conjunto con carbohidrato fermentable puede reducir este efecto, el almidón resistente previene la formación de aductos inducidos por la carne roja; esto asociado con el aumento de los niveles de AGCC y cambios en la composición de la microbiota (Le Leu et al., 2015). 
Identificar los efectos de la fibra dietética en la microbiota intestinal se complica por diferencias en las estructuras químicas, otros componentes de los alimentos, la variación del huésped y las metodologías de estudio. No obstante, algunos patrones similares son aumentos frecuentes en Bifidobacterium spp., Ruminococcus spp., Eubacterium spp. y Faecalibacterium prausnitzii (Sheflin et al., 2017).

La fermentabilidad de las celulosas dietéticas en el intestino humano varía según la fuente de alimento y la composición bacteriana intestinal. Las bacterias intestinales que degradan la celulosa se pueden dividir en productoras de metano, predominantemente Bacteroidetes, y no productoras de metano, predominantemente Firmicutes. Las especies que degradan la celulosa durante la digestión dependen de la estructura específica de la celulosa que se está consumiendo y pueden incluir Clostridium spp., Eubacterium spp., Ruminococcus spp. y Bacteroides spp. Tanto la celulosa como la hemicelulosa son componentes mayoritarios de las paredes celulares de las plantas y las hemicelulosas pueden dividirse en arabinoxilanos, xiloglucanos, $\beta$-glucanos, glucomananos y galactomananos. El tamaño molecular de las hemicelulosas juega un papel en sus efectos sobre la comunidad bacteriana intestinal (Sheflin et al., 2017).

Antes se creía que no era necesario incluir la fibra en la dieta (salvo por garantía para prevenir el estreñimiento) porque los humanos no producen enzimas para degradar celulosa o hemicelulosa, pero bacterias en la microbiota intestinal llevan a cabo esas funciones.

Hasta ahora, los modelos animales se han utilizado principalmente para investigar la influencia de las pectinas en la microbiota intestinal. En ratas, aumentó la abundancia de Bacteroides spp. con pectina de cítricos; y la de Anaeroplasma, Anaerostipes y Roseburia con pectina de manzana, que también disminuyó la abundancia de Alistipes y Bacteroides spp. Estos resultados sugieren que la estructura de las pectinas es un determinante del efecto sobre la microbiota intestinal y varía con la fuente de alimento (Sheflin et al., 2017).

Se han estudiado varias dietas, incluidas la occidental, libre de gluten, omnívora, vegetariana, vegana y la mediterránea, por su capacidad para modular la microbiota intestinal. Las dietas vegetariana y vegana están enriquecidas con alimentos fermentables a base de plantas. La dieta mediterránea es un marcado, pero no exclusivamente, estilo de dieta vegetariano, que ha demostrado ser beneficioso para el tratamiento de la obesidad, la diabetes tipo 2, enfermedades inflamatorias y enfermedades cardiovasculares (De Filippis et al., 2016). En varios estudios, una dieta occidental (alta en proteína y grasa animal, y baja en fibra) condujo a una marcada disminución en el número de bacterias totales y especies beneficiosas de Bifidobacterium y Eubacterium. El consumo de una dieta occidental se ha asociado con la producción de nitrosaminas promotoras del cáncer (Singh et al., 2017). La dieta mediterránea es considerada como una dieta sana y equilibrada. Se distingue por un perfil de ácidos grasos beneficiosos rico en ácidos grasos monoinsaturados y poliinsaturados, altos niveles de polifenoles y otros antioxidantes, alta ingesta de fibra y otros carbohidratos de bajo índice glucémico, y relativamente mayor ingesta de proteínas vegetales que de origen animal. Específicamente, aceite de oliva, frutas, cereales, nueces y otros vegetales; consumo moderado de pescado, carne de aves, y una menor ingesta de productos lácteos, carne roja, carne procesada y dulces caracterizan a la dieta mediterránea tradicional (Lopez-Legarrea et al., 2014). De Filippis et al. (2016) investigaron los beneficios potenciales de la dieta mediterránea comparando omnívoros, vegetarianos y veganos. Observaron que la mayoría de los vegetarianos y veganos, pero solo el $30 \%$ de los omnívoros, tenían una alta adherencia a la dieta mediterránea. Detectaron asociaciones significativas entre el grado de adherencia a la dieta mediterránea y el aumento de los niveles de AGCC fecales, bacterias Prevotella y otros Firmicutes. A su vez, la baja adherencia a la dieta mediterránea se asoció con $\mathrm{N}$-óxido de trimetilamina urinario elevado, que se asocia con riesgo de ateroesclerosis y desórdenes cardiovasculares.

La enfermedad cardiovascular representa la principal causa de muerte y morbilidad en el mundo. En la microbiota intestinal el metabolismo de la fosfatidilcolina, colina y L-carnitina produce trimetilamina, que luego es metabolizado a N-óxido de trimetilamina. Los alimentos ricos en lípidos fosfatidilcolina, que incluyen predominantemente huevos, leche, hígado, carnes rojas, aves de corral, mariscos y pescados, se cree que son las principales fuentes dietéticas de colina, y por lo tanto la producción de N-óxido de trimetilamina (Wang et al., 2011). La L-carnitina es un nutriente abundante en carnes rojas y contiene una estructura similar a la de la colina. Los humanos omnívoros producen más $\mathrm{N}$-óxido de trimetilamina que los vegetarianos y veganos (Koeth et al., 2013).

Otros estudios han demostrado que los alimentos que comprenden la dieta mediterránea típica ofrecen mejoría en relación con la obesidad, el perfil lipídico y la inflamación. Estos cambios pueden estar mediados por aumentos derivados de la dieta en Lactobacillus, Bifidobacterium, Prevotella, y disminuciones en Clostridium (Singh et al., 2017).

La dieta puede modificar la microbiota intestinal, lo que a su vez tiene un profundo impacto en la salud general. Este impacto puede ser beneficioso o perjudicial, 
dependiendo de la identidad relativa y la abundancia de poblaciones bacterianas constituyentes (Singh et al., 2017). La microbiota intestinal, compuesta por billones de organismos comensales no patógenos, sirve como filtro para nuestra mayor exposición medioambiental, lo que comemos (Wang et al., 2011).

A pesar de la relevancia evolutiva, pocos estudios comparan sistemáticamente microbiomas intestinales de primates humanos y no humanos. La comparación directa de microbiomas de primates (humanos y no humanos) ofrece información sobre qué factores moldearon el microbioma a lo largo del pasado evolutivo. Los datos que existen demuestran que, en contraste con ancestros comunes más recientes (simios africanos), los humanos tienen una baja diversidad de microbiota intestinal, mayor abundancia relativa de Bacteroides y menor abundancia relativa de Methanobrevibacter y Fibrobacter. Muchos de estas características están asociadas con la carnivoría en otros mamíferos, lo que sugiere que un cambio en la dieta humana hacia el consumo de carne en escalas de tiempo evolutivas puede haber estado acompañado por cambios microbianos intestinales asociados. $\mathrm{La}$ comparación de microbiomas de primates humanos y no humanos también proporciona una indicación de qué tan rápido está cambiando el microbioma humano. La composición del microbioma intestinal humano parece haber divergido del estado ancestral a un ritmo acelerado en comparación con la de los grandes simios. Algunas de las características de la evolución humana y la historia potencialmente responsable incluyen los alimentos cocidos, el advenimiento de la agricultura, el tamaño de la población y los aumentos de densidad (Davenport et al., 2017).

La asociación entre la dieta y la relación de parentesco (filogenia) en microbiomas de primates se hace eco de patrones más amplios de diversidad entre las comunidades intestinales de vertebrados. Las transiciones a herbivoría parecen tener efectos especialmente grandes en el microbioma. Los mamíferos con dietas herbívoras de evolución independiente albergan una microbiota similar. Además, algunos de los mismos genes y rutas que difieren en abundancia entre los microbiomas herbívoros y carnívoros, también cambian rápidamente en direcciones correspondientes en seres humanos que cambian de dietas vegetarianas a las omnívoras (Davenport et al., 2017).

El ARN ribosómico $16 \mathrm{~S}$ es la macromolécula más ampliamente utilizada en estudios de filogenia y taxonomía bacterianas para establecer las relaciones filogenéticas dentro del mundo procariota, causando un profundo impacto en la visión de la evolución y, como consecuencia, en la clasificación e identificación bacteriana (Rodicio y Mendoza, 2004). Billones de bacterias viven en el intestino de los primates, lo que contribuye al metabolismo, al desarrollo del sistema inmune y a la resistencia a patógenos. Las perturbaciones de esas bacterias están asociadas con enfermedades humanas metabólicas y autoinmunes que prevalecen en las sociedades occidentalizadas. Clayton et al. (2016) usaron la secuenciación de genes ARN ribosómico 16S en modelos de 2 especies de primates no humanos. Midieron las comunidades microbianas intestinales y la dieta en múltiples especies de primates que viven en estado salvaje, en un santuario y en completo cautiverio. Encontraron que el cautiverio y la pérdida de fibra dietética en primates no humanos estuvieron asociados con la pérdida de la microbiota intestinal nativa y la convergencia hacia el microbioma humano moderno, lo que sugirió, que procesos paralelos pueden estar impulsando la pérdida reciente de la biodiversidad microbiana central en humanos.

\section{Conclusiones}

La dieta modifica el microbioma intestinal y los efectos beneficiosos o perjudiciales de las dietas están mediados por la microbiota y dependen de la identidad relativa y la abundancia de poblaciones bacterianas constituyentes. La composición de la microbiota depende del tipo y la disponibilidad de sustratos proporcionados en la dieta habitual. Dietas basadas en plantas y animales tienen efectos diferentes sobre la ecología de la microbiota intestinal y sus productos metabólicos. Una microbiota favorable produce resultados en beneficio de la salud del huésped y se logra con dietas ricas en carbohidratos y bajas en proteínas/grasas. La dieta puede usarse para modular la composición y el metabolismo de la microbiota intestinal.

\section{Bibliografía}

Biagi, E., Franceschi, C., Rampelli, S., Severgnini, M., Ostan, R., Turroni, S., Consolandi, C., Quercia, S., et al. 2016. Gut microbiota and extreme longevity. Current Biology. 26(11):1480-1485.

Bian, G., Gloor, G.B., Gong, A.. Jia, Ch., Zhang, W., Hu, J., Zhang, H., Zhang, Y., et al. 2017. The gut microbiota of healthy aged Chinese is similar to that of the healthy young. mSphere. 2(5):e00327-17. $12 \mathrm{p}$.

Carvalho-Wells, A.L., Helmolz, K., Nodet, C., Molzer, C., Leonard, C., McKevith, B., Thielecke, F., Jackson, K.G., et al. 2010. Determination of the in vivo prebiotic potential of a maize-based whole grain breakfast cereal: a human feeding study. British Journal of Nutrition. 104(9):1353-1356.

Chen, T., Kim, Ch.Y., Kaur, A., Lamothe, L., Shaikh, M., Keshavarzian, A. and Hamaker, B.R. 2017. Dietary 
fibre-based SCFA mixtures promote both protection and repair of intestinal epithelial barrier function in a Caco-2 cell model. Food \& Function. 8(3):1166-1173.

Claesson, M.J., Jeffery, I.B., Conde, S., Power, S.E., O'Connor, E.M., Cusack, S., Harris, H.M.B., Coakley, M., et al. 2012. Gut microbiota composition correlates with diet and health in the elderly. Nature. 488:178-184.

Clayton, J.B., Vangay, P., Huang, H., Ward, T., Hillmann, B.M., Al-Ghalith, G.A., Travis, D.A., Long, H.T., et al. 2016. Captivity humanizes the primate microbiome. Proceedings of the National Academy of Sciences (USA). 13(37):10376-10381.

Costabile, A., Klinder, A., Fava, F., Napolitano, A., Fogliano, V., Leonard, C., Gibson, G.R. and Tuohy, K.M. 2008. Whole-grain wheat breakfast cereal has a prebiotic effect on the human gut microbiota: a double-blind, placebocontrolled, crossover study. British Journal of Nutrition. 99(1):110-120.

D'Argenio, V. and Salvatore, F. 2015. The role of the gut microbiome in the healthy adult status. Clinica Chimica Acta. 45(Part A):97-102.

Dao, M.C., Everard, A., Aron-Wisnewsky, J., Sokolovska, N., Prifti, E., Verger, E.O., Kayser, B.D., Levenez, F., et al. 2016. Akkermansia muciniphila and improved metabolic health during a dietary intervention in obesity: relationship with gut microbiome richness and ecology. Gut. 65(3):426-436.

Davenport, E.R., Sanders, J.G., Song, S.J., Amato, K.R., Clark, A.G. and Knight, R. 2017. The human microbiome in evolution. BMC Biology. 15:127. 12 p.

De Filippis, F., Pellegrini, N., Vannini, L., Jeffery, I.B., La Storia, A., Laghi, L., Serrazanetti, D.I., Di Cagno, R., et al. 2016. High-level adherence to a Mediterranean diet beneficially impacts the gut microbiota and associated metabolome. Gut. 65(11):1812-1821.

De Filippo, C., Cavalieri, D., Di Paola, M., Ramazzotti, M., Poullet, J.B., Massart, S., Collini, S., Pieraccini, G., et al. 2010. Impact of diet in shaping gut microbiota revealed by a comparative study in children from Europe and rural Africa. Proceedings of the National Academy of Sciences. 107(33):14691-14696.

David, L.A., Maurice, C.F., Carmody, R.N., Gootenberg, D.B., Button, J.E., Wolfe, B.E., Ling, A.V., Devlin, A.S., et al. 2014. Diet rapidly and reproducibly alters the human gut microbiome. Nature. 505:559-563.

Etxeberria, U., Milagro, F.I., González-Navarro, C.J. y Martínez, J.A. 2016. Papel en la obesidad de la microbiota intestinal. Anales de la Real Academia Nacional de Farmacia. 82:234-259.

Fava, F., Gitau, R., Griffin, B.A., Gibson, G.R., Tuohy, K.M. and Lovegrove, J.A. 2013. The type and quantity of dietary fat and carbohydrate alter faecal microbiome and short-chain fatty acid excretion in a metabolic syndrome 'at-risk' population. International Journal of Obesity.
$37: 216-223$

Flint, H.J., Scott, K.P., Louis, P. and Duncan, S.H. 2012. The role of the gut microbiota in nutrition and health. Nature Reviews Gastroenterology \& Hepatology. 9:577-589.

Fukuda, S., Toh, H., Hase, K., Oshima, K., Nakanishi, Y., Yoshimura, K., Tobe, T., Clarke, J.M., et al. 2011. Bifidobacteria can protect from enteropathogenic infection through production of acetate. Nature. 469:543-547.

Gerritsen, J., Smidt, H., Rijkers, G.T. and de Vos, W.M. 2011. Intestinal microbiota in human health and disease: the impact of probiotics. Genes \& Nutrition. 6(229):209240.

Gibson, G.R., Hutkins, R., Sanders, M.E., Prescott, S.L., Reimer, R.A., Salminen, S.J., Scott, K., Stanton, C., et al.2017. Expert consensus document: The International Scientific Association for Probiotics and Prebiotics (ISAPP) consensus statement on the definition and scope of prebiotics. Nature Reviews Gastroenterology \& Hepatology. 14:491-502.

Graf, D., Di Cagno, R., Fak, F., Flint, H.J., Nyman, M., Saarela, M. and Watz, B. 2015. Contribution of diet to the composition of the human gut microbiota. Microbial Ecology in Health and Disease. 26(1):26164. 11 p.

Hehemann, J.H., Correc, G., Barbeyron, T., Helbert, W., Czjzek, M. and Michel, G. 2010. Transfer of carbohydrate-active enzymes from marine bacteria to Japanese gut microbiota. Nature. 464:908-912.

Hill, C., Guarner, F., Reid, G., Gibson, G.R., Merenstein, D.J., Pot, B., Morelli, L., Canani, R.B., et al. 2014. The International Scientific Association for Probiotics and Prebiotics consensus statement on the scope and appropriate use of the term probiotic. Nature Reviews Gastroenterology \& Hepatology. 11:506-514.

Holscher, H.D. 2017. Dietary fiber and prebiotics and the gastrointestinal microbiota. Gut Microbes. 8(2):172184.

Hugon, P., Dufour, J.Ch., Colson, P., Fournier, P.E., Sallah, K. and Raoult, D. 2015. A comprehensive repertoire of prokaryotic species identified in human beings. The Lancet Infectious Diseases. 15(10):1211-1219.

Keim, N.L. and Martin, R.J. 2014. Dietary whole grainmicrobiota interactions: insights into mechanisms for human health. Advances in Nutrition. 5:556-557.

Kiefer, J., Beyer-Sehlmeyer, G. and Pool-Zobel, B.L. 2006. Mixtures of SCFA, composed according to physiologically available concentrations in the gut lumen, modulate histone acetylation in human HT29 colon cancer cells. British Journal of Nutrition. 96(5):803-810.

Klemashevich, C., Wu, Ch., Howsmon, D., Alaniz, R.C., Lee, K. and Jayaraman, A. 2014. Rational identification of diet-derived postbiotics for improving intestinal microbiota function. 26:85-90. 
Koeth, R.A., Wang, Z., Levison, B.S., Buffa, J.A., Org, E., Sheehy, B.T., Britt, E.B., Fu, X., et al. 2013. Intestinal microbiota metabolism of L-carnitine, a nutrient in red meat, promotes atherosclerosis. Nature Medicine. 19:576-585.

Korpela, K. 2018. Diet, microbiota, and metabolic health: trade-off between saccharolytic and proteolytic fermentation. Annual Review of Food Science and Technology. 9:65-84.

Le Leu, R.K., Winter, J.M., Christophersen, C.T., Young, G.P., Humphreys, K.J., Hu, Y., Gratz, S.W., Miller, R.B., et al. 2015. Butyrylated starch intake can prevent red meat-induced $\mathrm{O}^{6}$-methyl-2-deoxyguanosine adducts in human rectal tissue: a randomized clinical trial. British Journal of Nutrition. 114(2):220-230.

León-Marroú, M.E. 2011. Efecto bifidogénico de jalea de Lepidium meyenii Walp. "maca" en el recuento de Bifidobacterium bifidum en yogurt probiótico. Revista Venezolana de Ciencia y Tecnología de Alimentos. 2(1):094-107.

Levine; M.E., Suarez, J.A., Brandhorst, S., Balasubramanian, P., Cheng, C.W., Madia, F., Fontana, L., Mirisola, M.G., et al. 2014. Low protein intake is associated with a major reduction in IGF-1, cancer, and overall mortality in the 65 and younger but not older population. Cell Metabolism. 19(3):407-417.

Ley, R.E., Hamady, M., Lozupone, C., Turnbaugh, P.J., Ramey, R.R., Bircher, J.S., Schlegel, M.L., Tucker, T.A., et al. 2008. Evolution of mammals and their gut microbes. Science. 320(5883):1647-1651.

Lockyer, S. and Nugent, A.P. 2017. Health effects of resistant starch. Nutrition Bulletin. 42(1):10-41.

Lopez-Legarrea, P., Fuller, N.R., Zulet, M.A., Martinez, J.A. and Caterson, ID. 2014. The influence of Mediterranean, carbohydrate and high protein diets on gut microbiota composition in the treatment of obesity and associated inflammatory state. Asia Pacific Journal of Clinical Nutrition. 23(3):360-368.

Lopez-Siles, M., Duncan, S.H., Garcia-Gil, L.J. and MartinezMedina, M. 2017. Faecalibacterium prausnitzii: from microbiology to diagnostics and prognostics. The ISME Journal. 11:841-852.

Macfarlane, G.T. and Macfarlane, S. 2012. Bacteria, colonic fermentation, and gas-trointestinal health. Journal of AOAC International. 95(1):50-60.

Mah, K.W., Sangsupawanich, P., Tunyapanit, W., van Bever, H., Shek, L.P., Chua, K.Y. and Lee, B.W. 2008. Gut microbiota of children living in rural south Thailand and urban Singapore. Allergology International. 57(1):6571.

Mitsou, E.K., Kougia, E., Nomikos, Tz., Yannakoulia, M., Mountzouris, K.C. and Kyriacou, A. 2011. Effect of banana consumption on faecal microbiota: a randomised, controlled trial. Anaerobe. 17(6):384-387.
Muegge, B.D., Kuczynski, J., Knights, D., Clemente, J.C., González, A., Fontana, L., Henrissat, B., Knight, R. and Gordon, J.I. 2011. Diet drives convergence in gut microbiome functions across mammalian phylogeny and within humans. Science. 332(6032):970-974.

National Center for Complementary and Integrative Health (NCCIH). 2018. Probiotics. U.S. Department of Health \& Human Services, National, Institutes of Health. https://nccih.nih.gov/health/probiotics

Nishijima, S., Suda, W., Oshima, K., Kim, S.W., Hirose, Y., Morita, H. and Hattori, M. 2016. The gut microbiome of healthy Japanese and its microbial and functional uniqueness. DNA Research. 23(2):125-133.

Parajuli, A., Grönroos, M., Kauppi, S., Płociniczak, T., Roslund, M.I., Galitskaya, P., Laitinen, O.H., Hyöty, H., et al. 2017. The abundance of health-associated bacteria is altered in PAH polluted soils-Implications for health in urban areas? PLoS ONE. 12(11):e0187852.

Patel, S. and Goyal, A. 2012. The current trends and future perspectives of prebiotics research: a review. 3 Biotech. 2(2):115-125.

Rajoka, M.S.R., Shi, J., Mehwish, H.M., Zhu, J., Li, Q., Shao, D., Huang, Q. and Yang, H. 2017. Interaction between diet composition and gut microbiota and its impact ongastrointestinal tract health. Food Science and Human Wellness. 6(3):121-130.

Rodicio, M. del R. y Mendoza, M del C. 2004. Identificación bacteriana mediante secuenciación del $\mathrm{ARNr}$ 16S: fundamento, metodología y aplicaciones en microbiología clínica. Enfermedades Infecciosas y Microbiología Clínica. 22(4):238-245.

Schnorr, S.L., Candela, M., Rampelli, S., Centanni, M., Consolandi, C., Basaglia, G., Turroni, S., Biagi, E., et al . 2014. Gut microbiome of the Hadza hunter-gatherers. Nature Communications. 5:3654. 12 p.

Sheflin, A.M., Melby, C.L., Carbonero, F. and Weir, T.L. 2017. Linking dietary patterns with gut microbial composition and function. Gut Microbes. 8(2):113-129.

Shinohara, K., Ohashi, Y., Kawasumi, K., Terada, A. and Fujisawa, T. 2010. Effect of apple intake on fecal microbiota and metabolites in humans. Anaerobe. 16(5):510-515.

Singh, R.K., Chang, H.W., Yan, D., Lee, K.M., Ucmak, D., Wong, K., Abrouk, M., Farahnik, B., et al. 2017. Influence of diet on the gut microbiome and implications for human health. Journal of Translational Medicine. 15:73. $17 \mathrm{p}$.

Slavin, J. 2013. Fiber and prebiotics: mechanisms and health benefits. Nutrients. 5(4):1417-1435.

Świątecka, D., Narbad, A., Ridgway, K.P. and Kostyra, H. 2011. The study on the impact of glycated pea proteins on human intestinal bacteria. International Journal of Food Microbiology. 145(1):267-272.

Thursby, E. and Juge, N. 2017. Introduction to the human gut 
microbiota. Biochemical Journal. 474(11):1823-1836.

Walker, A.W., Ince, J., Duncan, S.H., Webster, L.M., Holtrop, G., Ze, X., Brown, D., Stares, M.D., et al. 2011. Dominant and diet-responsive groups of bacteria within the human colonic microbiota. The ISME Journal. 5:220-230.

Wang, B., Yao, M., Lv, L., Ling, Z. and Li, L. 2017. The human microbiota in health and disease. Engineering. 3(1):71-82.

Wang, Z., Klipfell, E., Bennett, B.J., Koeth, R., Levinson, B.S., DuGar, B., Feldstein, A.E., Britt, E.B., et al. 2011. Gut flora metabolism of phosphatidylcholine promotes cardiovascular disease. Nature. 472:57-63.

Wu, G.D., Chen, J., Hoffmann, Ch., Bittinger, K., Chen, Y.Y., Keilbaugh, S.A., Bewtra, M., Knights, D., et al. 2011. Linking long-term dietary patterns with gut microbial enterotypes. Science. 334(6052):105-108.

Yatsunenko, T., Rey, F.E., Manary, M.J., Trehan, I., Dominguez-Bello, M.G., Contreras, M., Magris, M., Hidalgo, G., et al. 2012. Human gut microbiome viewed across age and geography. Nature. 486:222-227. 